\title{
RESEARCH ON PRECISION IRRIGATION IN WESTERN SEMIARID AREA OF HEILONGJIANG PROVINCE BY INTERPRETING DATA SOURCE SPATIAL DISTRIBUTION
}

\author{
Qiang Fu ${ }^{*}$, Qiuxiang Jiang, Zilong Wang \\ College of Water Conservancy \& Architecture, Northeast Agricultural University, Harbin, \\ Heilongjiang Province, P. R. China 150030 \\ * Corresponding author, Address: College of Water Conservancy \& Architecture, Northeast \\ Agricultural University, Harbin 150030, Heilongjiang Province, P. R. China, Tel: +86- \\ 451-55191294,Email: fuqiang@neau.edu.cn
}

\begin{abstract}
Geostatistics and geographic information system (GIS) were performed to characterize the spatial variability of soil water characteristics in western semiarid area of Heilongjiang Province and delineate the spatial distributions of the variables. On the basis of data source spatial distribution and professional knowledge, the study site was divided into four irrigation management zones. Then stratified sampling method and optimal distribution method were used to calculate the rational sampling number in each sub-zone and rational sampling scheme was designed combing with the ranges of regionalized variables. During the course of practicing precision irrigation, irrigation scheme can be designed by measuring natural water content in each sub-zone and comparing with saturated water content, field water capacity and wilting point in the same area.
\end{abstract}

Key words: management zone, precision irrigation, sampling scheme, spatial variability

\section{INTRODUCTION}

Precision irrigation, based on $3 \mathrm{~S}$ technique and geostatistics theory, is an integrated irrigation technology system to real-timely and appropriately

Please use the following format when citing this chapter:

Fu, Q., Jiang, Q. and Wang, Z., 2009, in IFIP International Federation for Information Processing, Volume 293, Computer and Computing Technologies in Agriculture II, Volume 1, eds. D. Li, Z. Chunjiang, (Boston: Springer), pp. 135-144. 
irrigation according to soil moisture and water requirement of various crops in different growth periods, by utilizing macroscopic control of RS, functions (collecting, storing, analyzing and outputting element data required by ground or plot) of GIS and ground precision measurement of GPS, then matching ground information transformation and real-time control system (Cheng, 2004).

Owing to various and complex demands of precision irrigation (soil moisture, water requirement condition and variable irrigation technique), it is difficult to research and practice precision irrigation. Few researches about precision irrigation were reported abroad, and it was in starting stage in China (Tian et al., 2002). Liu et al. (2006) expounded the research significance and prospect of precision irrigation in China. Liu (2000) used GPS water saving irrigation system to study precision irrigation. Sun et al. (2004) practiced real-time and appropriate precision irrigation during whole cotton growth period based on under-film automatic tickle irrigation system in cotton field and provided hardware supports for precision irrigation. $\mathrm{Hu}$ (2004) established real-time irrigation forecast model for irrigation district and obtained precision prediction results. Han et al. (2003 and 2004) made a lot of researches on variable irrigation sprinkler and developed an impact sprinkler with non-circular spray field. A great deal of researches were made on precision irrigation system and equipment by domestic scholars, but few studies, however, reported the quantitative research on field precision irrigation management zone and irrigation water use.

Thus, the objectives of the study were to characterize the spatial variability of soil water characteristics in western semiarid area of Heilongjiang Province, to delineate irrigation management zone for study site based on data source spatial distribution by utilizing geostatistics, GIS and sampling technique, and to practice precision irrigation by measuring natural water content in each sub-zone.

\section{MATERIALS AND METHODS}

\subsection{Site description and soil sampling}

The study was conducted on a soybean field of 1 ha in the dry cultivation techniques demonstration district of Chahayang Farm, which is in the western semiarid area of Heilongjiang Province. It is located in the cold temperate zone, continental monsoon and semiarid agricultural climate region, and is windy and arid in spring. Thus precision irrigation practiced in the region is magnitude. 
A grid-sampling scheme was imposed on the field to collect 300 soil samples from three layers in the topsoil $(0-30 \mathrm{~mm})$ at an interval of $10 \mathrm{~m}$ in the autumn of 2006 after crop harvesting. One representative sample was collected at the center of each grid and geo-referenced using a Trimble global positioning system (GPS) with differential correction. Five indices, such as natural water content (NWT), field moisture capacity (FMC), saturation moisture content (SMC), wilting point (WT) and soil dry bulk density (SDBD), were measured for three layers soil samples in each sampling position, and the mean of them was considered as the soil water characteristics values of the point.

\section{$2.2 \quad$ Geostatistics}

In 1970s, geostatistical method was introduced into soil science field, which overcame the deficiency researching spatial variability of soil characteristics on the basis of classical Fisher statistics theory. Geostatistics is a branch of science based on a series of concepts (regionalized variable, random function, stationarity hypothesis, etc.), to take semi-variogram as main tool and kriging interpolation method as instrument, to study natural phenomena having random and structural spatial distribution or spatial correlation and dependence (Hou et al., 1993). Semi-variogram and kriging interpolation map in geostatistics can be used to determine variation extent and spatial correlation scale of soil properties, to estimate spatial distributions of soil characteristics and to provide guiding significance. Presently, it is one of the trends to apply the theory and method of geostatistics in quantitative research on soil spatial variability.

\subsection{Sampling technique}

Under a range of sampling error, different sampling method is needed for various sample numbers and requirements to reflect the property of population as much as possible with the least samples. Simple random sampling and stratified sampling are the most adopted sampling techniques. Random sampling is simple and intuitionistic, but has low estimation efficiency for population, while stratified sampling has higher estimation precision, which can estimate population index and layered index simultaneously and carry out different sampling methods among layers. Thus, stratified sampling method was performed in the study for sampling investigation of the soil water characteristics (Jin et al., 2002). The optimal 
distribution method is used to determine the sampling number of each layer. The calculation equations are as follows.

Total sample size: $n=\frac{\left(\sum W_{h} S_{h}\right)^{2}}{V+\frac{\sum W_{h} S_{h}^{2}}{N}}$,

Distribution of sample size among layers: $n_{h}=\frac{N_{h} S_{h}}{\sum_{h=1}^{L} N_{h} S_{h}} \times n$,

Where: $W_{h}=\frac{N_{h}}{N}$ and $V=\left(\frac{d}{t}\right)^{2}=\left(\frac{r \bar{Y}}{t}\right)^{2} ; W_{h}, N_{h}$ and $S_{h}$ are the weight, observation number and standard deviation of the $h$ th layer respectively; $N$ is the observation number of population; $V$ is the variance from sample estimation; $d$ is absolute error; $r$ is the relative error; $\bar{Y}$ is the mean value of population and $t$ is the bilateral $\alpha$ quantile of standard normal distribution.

\section{RESULTS AND DISCUSSION}

\subsection{Spatial variability analysis of data source}

The contents of spatial variability analysis include calculating semivariogram, fitting semi-variance model and estimating non-sampling area for regionalized variable (Zhang, 2006). Through analyzing the parameters of semi-variance model, we can sufficiently find out the variation condition and influencing factors of regionalized variable. Spatial partial estimation is to use kriging method to interpolate in non-sampling area and delineate spatial distribution for regionalized variable, which can intuitionisticly illuminate the spatial distribution situation of regionalized variable. Calculating semivariogram and fitting theoretical model were conducted in a geostatistical software (GS+) and the results are listed in Table 1. ArcGIS software is use to complete spatial partial estimation and the maps are showed in Fig.1.

Table 1. Models and parameters of semivariograms for soil water characteristics

\begin{tabular}{ccccccc}
\hline SWC ${ }^{\text {a) }}$ & Fittedmodel & $\begin{array}{c}\text { Nugget variance } \\
\left(\mathrm{C}_{0}\right)\end{array}$ & $\begin{array}{c}\text { Sill variance } \\
\left(\mathrm{C}_{0}+\mathrm{C}\right)\end{array}$ & $\begin{array}{c}\text { Nugget/Sill Ratio } \\
{\left[\mathrm{C}_{0} /\left(\mathrm{C}_{0}+\mathrm{C}\right)\right](\%)}\end{array}$ & Range(m) & CD \\
\hline NWC & Exponential & 0.68 & 2.30 & 29.52 & 30.3 & 0.967 \\
FMC & Spherical & 0.57 & 2.63 & 21.49 & 23.4 & 0.938 \\
SMC & Spherical & 4.80 & 23.19 & 20.70 & 19.1 & 0.878 \\
WP & Spherical & 0.11 & 0.53 & 20.64 & 94.2 & 0.934 \\
SBDB & Spherical & 0.001 & 0.005 & 22.92 & 19.2 & 0.829 \\
\hline
\end{tabular}

a) SWC, soil water characteristics; $\mathrm{CD}$, coefficient of determination 


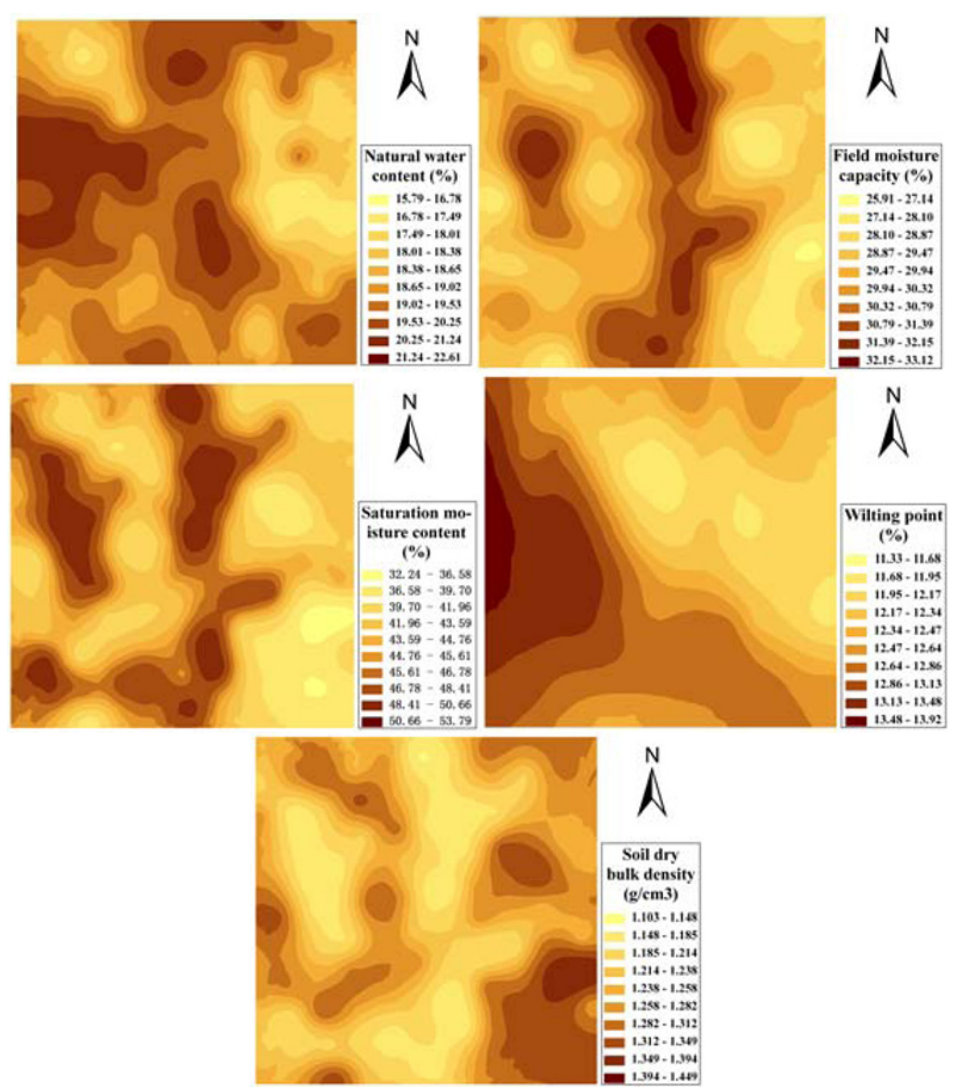

Fig.1. Spatial distributions of soil water characteristics

The optimal theoretical model of natural water content was exponential model, whereas the other soil water characteristics were all best fitted to spherical models. The coefficient of determination of soil water characteristics were greater than 0.829 indicating a high degree of modeling confidence. The nugget/sill ratio $\left[\mathrm{C}_{0} /\left(\mathrm{C}_{0}+\mathrm{C}\right)\right]$ can describe the proportions of random factors and structural factors to system total variability, and can characterize the variable degree of regionalized variables more intuitionisticly comparing with the coefficient of variation (Jiang et al., 2007). The nugget/sill ratio of natural water content was $29.52 \%$ suggesting moderate variability $(25 \%-75 \%)$, while the other soil water characteristics showed weak variability $(0-25 \%)$, which indicated that in the variation of natural water content, random factors accounted for a large percentage, namely, it was mainly affected by climate and artificial factors. For the five characteristics the ranges have changed greatly, and wilting point had the 
biggest range of $94.2 \mathrm{~m}$ while saturation moisture content had the smallest range of $19.1 \mathrm{~m}$, which indicated that the grid spacing $(10 \mathrm{~m})$ in the study was adequate for characterizing the spatial variability of soil water characteristics.

Field moisture capacity, saturation moisture content and soil dry bulk density had a similar spatial distribution presenting bandings, and the last index was negatively correlated with the other two indices, namely, soil dry bulk density had small values in the region where the other indices with big values. Through the course of correlation analysis, the correlation coefficients of soil dry bulk density to saturation moisture content and field moisture capacity were -0.98 and -0.85 respectively, which confirmed the spatial variability relations among them. The spatial distributions of natural water content and wilting point presented sheets.

\subsection{Delineating precision irrigation management zone}

Implementing different irrigation schemes based on various soil moistures is the aim of precision irrigation. For field moisture capacity, saturated moisture content and wilting point are important indices to determine irrigation water use and whether to irrigate, the three water characteristics are essential during delineating irrigation management zone. Homogeneous soil water characteristics in the same sub-zone and easy field management are principles to delineate the study site. Owing to sheet spatial distribution of FMC and SMC and north-south ridge in the field, the study area was divided into four oblong sub-zones listed in Fig.2, where zone III had the biggest area of $3000 \mathrm{~m}^{2}$, zone II had the smallest area of $2000 \mathrm{~m}^{2}$, and zone I and zone IV had the equal area of $2500 \mathrm{~m}^{2}$.

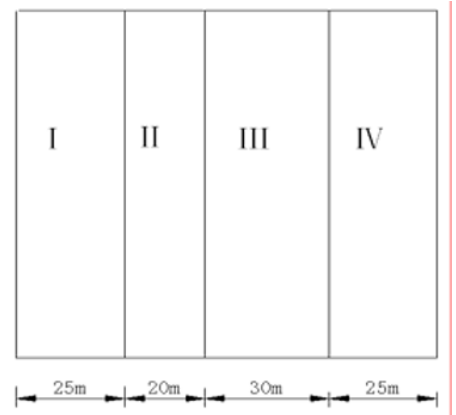

Fig.2: Sketch map of irrigation management zone for study site

For differences existed among soil water characteristics of each sub-zone after delineation, statistics analysis is needed to realize them roundly. Table 2 lists the results. Through comparison of mean values, the sequencing of NWC was zone I > zone III > zone II > zone IV, namely, soil moisture of zone I was best when samples were collected, while that of SBDB was zone 
IV $>$ zone II > zone I > zone III. The smallest values of NWC, FMC, SMC and WP in zone IV indicated that the sub-zone had bad soil moisture condition and water retaining capacity owing to the high SBDB in the area leading to dense granule sequencing and small permeability, so deep tillage is essential for the area to decrease SBDB. FMC and SMC were biggest and SBDB was smallest in zone III, which illuminated that the surface soil of the area had strong water capacity and good quality. After analyzing the variation coefficient in each sub-zone, we found that the variation coefficients of all soil water characteristics expect for NWC decreased in different extent after delineation, which showed that differences in the same sub-zone were smaller than that of total area.

Table 2. Statistical eigenvalue of soil water characteristics in each sub-zone

\begin{tabular}{llllllll}
\hline \multirow{2}{*}{ Sub-zone } & $\begin{array}{l}\text { Sample } \\
\text { number }\end{array}$ & SE & $\begin{array}{l}\text { NWC } \\
(\%)\end{array}$ & $\begin{array}{l}\text { FMC } \\
(\%)\end{array}$ & $\begin{array}{l}\text { SMC } \\
(\%)\end{array}$ & $\begin{array}{l}\text { WP } \\
(\%)\end{array}$ & $\begin{array}{l}\text { SBDB } \\
\left(\mathrm{g} / \mathrm{cm}^{3}\right)\end{array}$ \\
\hline \multirow{2}{*}{ Zone I } & \multirow{2}{*}{225} & $\begin{array}{l}\text { Mean } \\
\text { CV }(\%)\end{array}$ & $\begin{array}{l}19.45 \\
4.88\end{array}$ & $\begin{array}{l}29.64 \\
3.14\end{array}$ & $\begin{array}{l}45.33 \\
5.85\end{array}$ & $\begin{array}{l}13.12 \\
1.238\end{array}$ & 3.23 \\
\hline \multirow{2}{*}{ Zone II } & \multirow{2}{*}{180} & Mean & 19.27 & 29.8 & 43.69 & 12.64 & 1.247 \\
& & CV $(\%)$ & 3.22 & 2.28 & 4.92 & 3.01 & 2.41 \\
\hline \multirow{2}{*}{ Zone III } & \multirow{2}{*}{270} & Mean & 19.32 & 30.74 & 45.78 & 12.38 & 1.216 \\
& \multirow{2}{*}{ Zone IV } & CV $(\%)$ & 3.67 & 2.99 & 6.14 & 2.42 & 3.29 \\
\hline \multirow{2}{*}{ Total area } & \multirow{2}{*}{900} & Mean & 18.46 & 28.67 & 40.53 & 12.28 & 1.292 \\
& & CV $(\%)$ & 4.01 & 2.65 & 6.81 & 1.95 & 3.10 \\
\hline
\end{tabular}

a) SE, statistical eigenvalue; $\mathrm{CV}$, coefficient of variation

Single factor unequal repeated test was conducted based on grid data among sub-zones to estimate whether differences were remarkable or not. The results listed in Table 3 showed very significant difference between subzones, where the value of $F$ of WP was biggest while that of NWC was smallest. Though the significance of NWC was not strong, it met the variance test of very significance. The results of variance analysis illuminated that delineation based on spatial distributions of soil water characteristics showed good homogeneity in a sub-zone and significant heterogeneity between sub-zones and obtained favorable results.

Table 3. Single factor variance analysis of soil water characteristics among sub-zones

\begin{tabular}{cccccc}
\hline Statistics test & NWC $(\%)$ & FMC $(\%)$ & SMC $(\%)$ & WP $(\%)$ & SBDB $\left(\mathrm{g} / \mathrm{cm}^{3}\right)$ \\
\hline $\mathrm{F}$ & 73.71 & 220.22 & 181.71 & 310.69 & 140.28 \\
$\mathrm{Pr}>\mathrm{F}$ & $<0.0001$ & $<0.0001$ & $<0.0001$ & $<0.0001$ & $<0.0001$ \\
Significance & Very & Very & Very & Very & Very \\
\hline
\end{tabular}




\subsection{Designing sampling scheme}

Rational sampling number and spatial position of sampling point are two main aspects that should be considered in design of sampling scheme (Wollenhaupt et al., 1997). Due to various mean, coefficient of variation (CV) and standard deviation between sub-zones, optimal distribution method of stratified sampling was carried out to calculate and distribute rational sampling number for sub-zones. Results obtained at the confidence level of $95 \%$ and in the relatively tolerable error of $5 \%$ are listed in Table 4 . The rational sampling quantity ascertained by stratified sampling method has decreased by $88 \%-97 \%$ compared with the original in the study site, which consumedly saved manpower and material resources and reduced invest for precision irrigation practice.

Table 4. Rational sampling number of each sub-zone

\begin{tabular}{lccccc}
\hline \multicolumn{1}{c}{ Sub-zone } & NWC & FMC & SMC & WP & SBDB \\
\hline Zone I & 2 & 1 & 4 & 1 & 1 \\
Zone II & 2 & 1 & 3 & 0 & 1 \\
Zone III & 2 & 1 & 4 & 1 & 2 \\
Zone IV & 2 & 1 & 4 & 1 & 1 \\
Total zone & 8 & 4 & 15 & 3 & 5 \\
\hline
\end{tabular}

Rational sampling scheme has to match rational sampling number and ensure distance between samples larger than range of the variable. On the basis of these principles, sampling scheme was designed and showed in Fig.3. The three sampling points of WP located at the intersections of northwest to southeast diagonal and the midlines of zone I, zone III and zone IV, respectively. The four sampling points of FMC located at the intersections of southwest to northeast diagonal and the midlines of all four sub-zones. The distances from the sampling point of SCM at northeast corner to north side of the field, from sampling point at southwest corner to south side, and from point to point on the north-south direction were $10 \mathrm{~m}$, $15 \mathrm{~m}$ and $25 \mathrm{~m}$, respectively. The spatial locations of sampling point of NWC are showed in Table 5.

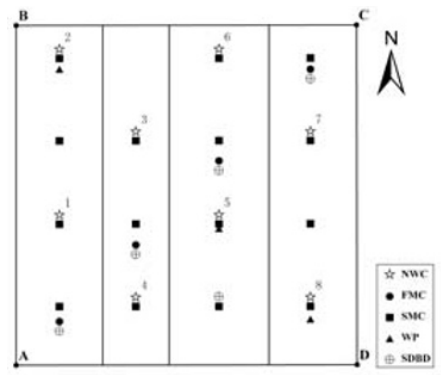

Fig.3: Sampling scheme map for the study site 
Heilongjiang Province by Interpreting Data Source Spatial Distribution

Table 5. Spatial positions for natural water content in the scheme

\begin{tabular}{ccccccc}
\hline \multirow{2}{*}{ Point } & \multicolumn{2}{c}{ Relative coordinates $(\mathrm{m})$} & & \multirow{2}{*}{ Point } & \multicolumn{2}{c}{ Relative coordinates $(\mathrm{m})$} \\
\cline { 2 - 3 } & $\mathrm{X}$ & $\mathrm{Y}$ & & & $\mathrm{X}$ & $\mathrm{Y}$ \\
\hline $\mathrm{A}$ & 0 & 0 & 5 & 60 & 40 \\
1 & 12.5 & 40 & 6 & 60 & 90 \\
2 & 12.5 & 90 & 7 & 87.5 & 65 \\
3 & 35 & 65 & 8 & 87.5 & 15 \\
4 & 35 & 15 & $\mathrm{C}$ & 100 & 100 \\
\hline
\end{tabular}

\subsection{Practicing precision irrigation}

Because NWC extremely influenced by climate has strong temporal variability, it just reflects the soil moisture condition when sampling scheme is performed, while the other soil water characteristics related to soil parent material and grain composition have relatively temporal stability. Thus, NWC measurements are available and efficient for precision irrigation decision-making. The measurement of NWC can be performed based on field soil sampling or soil moisture monitoring system installed in field for long term monitoring, where the burying quantity and location of monitoring system can be carried out on the basis of the sampling scheme of NWC.

During the course of practicing irrigation, comparing the monitored means of NWC of each sub-zone in the study site with the means of FMC, WP and SMC in Table 2, we can then make a decision on precision irrigation, namely, when NWC is between FMC and SMC, irrigation is unnecessary, and when it is less than FMC and approaching WP, irrigation is needed and the upper irrigation limit is FMC in each sub-zone. Additionally, when water supply is plenteous, $70 \%$ of FMC can be taken as the lower irrigation limit, however, if water-saving irrigation techniques are adopted, the lower irrigation limits are the lowest values of appropriated moistures in different growing stages obtained according to demands of various crops and local water-saving irrigation experiments of main crops (Hu, 2004).

\section{CONCLUSIONS}

Aiming at the present situation of fewer researches on precision irrigation abroad and in home, on the basis of spatial variability of soil water characteristics, we combined spatial distributions of the variables with professional knowledge to divide the study area into four irrigation management zones and the analysis results indicated the delineation for the 
study site was reasonable. To ensure the representation of sampling points, geostatistics and stratified sampling method were integrated to design rational sampling scheme. During the course of practicing precision irrigation, soil moisture monitoring system can be installed in the field based on the sampling scheme, and different irrigation schemes can be design by comparing the measurements of NWC with FMC, SMC and WP in each subzone.

\section{ACKNOWLEDGEMENTS}

Project supported by the Science \& Technology Tackle Key Problem Program of Heilongjiang (No.GB06B106-7).

\section{REFERENCES}

D. J. Liu, J. X. Feng. Precision irrigation and its prospect analysis. Water Saving Irrigation, 2006, 43(2): 43-44.

G. S. Liu. Research on the GPS water-saving irrigation system. Transactions of the CSAE, 2000, 16(2): 24-27.

J. C. Cheng. Precision Agriculture Technique and Its Application. Science Press, Beijing. 2004, 352pp.

J. C. Tian, B. F. Han, B. L. Wang. Research on precision irrigation. Journal of Ningxia Agricultural College, 2002, 23(2): 33-36.

J. R. Hou, Z. N. Yin. Theory and Application of Statistical Prediction of Ore Deposits and Geostatistics. Geology Press, Beijing, China, 1993.

L. Hu. Real-time forecast model of irrigation in irrigation districts. Nanjing, China, HeHai University, 2004.

L. Sun, J. Wang, X. Chen. Experiment demonstration research on precision irrigation index system of cotton in Xinjiang. China Cotton, 2004, 31(9): 22-24.

N. C. Wollenhaupt, D. J. Mulla and C. A. Crawford. Soil sampling and interpolation techniques for mapping spatial variability of soil proterties. In Pierce F J and Sadler E J (eds.), The State of Site Specific management for Agriculture, Am.Soc.Agron., Madison, WI. 1997, pp19-53.

Q. X. Jiang, Q. Fu, Z. L. Wang. Research on spatial variability of soil water characteristics in western semiarid area of Heilongjiang Province. Journal of Soil and Water Conservation, 2007, 21(5): 118-121.

R. D. Zhang. Theory and Application of Spatial Variability. Science Press, Beijing, 2005, $187 \mathrm{pp}$.

W. T. Han, P. T. Wu, H. Ma, et al. Review on irrigated area profile modeling and variablerate precision sprinkle irrigation technique. Transactions of the CSAE, 2004, 20(1):16-19.

W. T. Han, P. T. Wu, H. Ma, et al. Variable-rate sprinklers for precision irrigation on square area. Agricultural Research in the Arid Areas, 2003, 21(2):105-107.

Y. J. Jin, Y. Jiang, X. Y. Li. Sampling technology. Renmin Press, Beijing, China, 2002. 